\title{
SOIL LOAD ON PLASTIC PIPE AND ITS INFLUENCE ON LIFETIME
}

\author{
PODUŠKA Jan ${ }^{1,2}$, HUTǍ̌ Pavel ${ }^{2}$, FRANK Andreas ${ }^{3}$, KUČERA Jaroslav ${ }^{4}$, SADÍLEK \\ Jiřri $^{4}$, PINTER Gerald ${ }^{5}$, NÁHLÍ́K Luboš ${ }^{6}$
}

\author{
${ }^{1}$ Institute of Solid Mechanics, Mechatronics and Biomechanics - Faculty of Mechanical Engineering, \\ BUT, Technická 2896/2, 61669 Brno, Czech Republic, e-mail: poduska@ipm.cz \\ ${ }^{2}$ Institute of Physics of Materials - AS CR, Žižkova 513/22, 61662 Brno, Czech Republic,e-mail: hutar@ipm.cz \\ ${ }^{3}$ Polymer Competence Center Leoben, Roseggerstrasse 12, A-8700 Leoben, Austria, \\ e-mail: andreas.frank@pccl.at \\ ${ }^{4}$ Polymer Institute Brno, Tkalcovská 53/2, 60200 Brno, Czech Republic, \\ e-mail: jaroslav.kucera@polymer.cz,jiri.sadilek@polymer.cz \\ ${ }^{5}$ Chair of Materials Science and Testing of Polymers - Montanuniversität Leoben, Otto Glöckel-Straße 2/II, \\ A-8700 Leoben, Austria, e-mail: gerald.pinter@unileoben.ac.at \\ ${ }^{6}$ CEITEC IPM, Žižkova 513/22, 61662 Brno, Czech Republic, e-mail: nahlik@ipm.cz.
}

\begin{abstract}
Lifetime of plastic pipes can be estimated by integration of a power law describing the crack kinetics. However, this procedure requires an FEM (finite element method) calculation of the possible crack propagation in the pipe to obtain stress intensity factor dependency on the crack length. It is very important for the simulation to consider every possible load that is acting on the pipe. This contribution deals with FEM modelling of a pipe that is loaded by internal pressure, residual stresses and soil loads. Comparison of the factors and pipe lifetime estimation is carried out.
\end{abstract}

KEYWORDS: Plastic pipe, Lifetime estimation, Soil loads, Residual stress.

\section{Introduction}

It is mandatory for plastic pressure pipes made of polyethylene (PE) to withstand at least 50 years in operation. The ability of a plastic pipe to stay in operation for such a long period of time is usually given by the resistance of the pipe material against the so-called slow crack growth (often abbreviated as SCG). Slow crack growth is the most common mechanism of failure of polyethylene pressure pipes [1]. It consists of crack initiation and very slow propagation through the pipe wall in the radial direction. The crack initiates at the inner surface of the pipe, when static hoop stress (tangential stress caused by the internal pressure) acts on a surface defect. When the crack front reaches the outer surface, the pipe bursts. SCG is a process that happens even at very low load levels.

The constant effort to improve the production technology of the pipe materials has led to creation of durable pipe materials (category PE100 RC) that are significantly resistant against SCG. Pipes made of these materials are expected to be able to exceed 100 years in operation [2]. However, it is very difficult to prove such a prediction by testing. The hydrostatic pressure test - a common way of testing durability of pipes by loading them by water pressure and measuring the time to failure - can take years to produce useful results, even when the temperature of the test environment is $80{ }^{\circ} \mathrm{C}$, which accelerates the slow crack growth.

There are also different methods of testing the SCG resistance of various pipe materials, that do not take so much time. These tests are usually carried out on notched samples. The samples are loaded by a constant tensile force in a specified testing environment (the environment is designed to accelerate the crack growth - e.g. by higher temperature or by 
presence of an aggressive chemical) and time to failure is measured - the most frequently used are the FNCT test [3] and the PENT test [4]. Although these tests provide information about the resistance against SCG, they cannot be used to predict lifetime of an actual pipe.

A convenient way of obtaining lifetime prediction of a certain pipe is to use the approach of linear elastic fracture mechanics, which is applicable to SCG, because the process zone of the crack is very small, so the small-scale yielding condition is met $[5,6]$. The kinetics of SCG in PE can be measured and described by a power-law

$$
\frac{\mathrm{d} a}{\mathrm{~d} t}=A\left(K_{I}(a)\right)^{m}
$$

where $\mathrm{d} a / \mathrm{d} t$ is the crack growth rate, the $K_{I}(a)$ is the stress intensity factor as a function of crack length $a, A$ and $m$ are material constants obtained by crack kinetics measurements. Lifetime estimation of a pipe can be calculated by integration of the modified Paris-Erdogan equation, if the function of $K_{I}(a)$ is known - this function must be determined by FEM (finite element method) simulation of crack propagation in a pipe. A significant advantage of this approach is, that the stress intensity factor function can be calculated for various cases of loads acting on the pipe.

This contribution deals with FEM simulation of crack growth in a PE pipe loaded by internal pressure, residual stress and external pressure caused by the soil, in case the pipe is buried. The above-mentioned stress intensity factor function is calculated. The influence of each of the loads on the lifetime is evaluated and discussed.

\section{Residual stress in a PE pipe}

Residual stress is an important factor, that must be considered, when simulating a pressure pipe made of PE. The residual stress is a product of uneven cooling after the extrusion of a PE pipe. The outer surface of PE pipe after extrusion is usually sprayed with water, while the inner surface remains dry and cools down slowly. This results in tensile residual stress developing on the inner surface and compressive at the outer surface [7]. The stress develops in tangential direction and in axial direction too. The tangential residual stress is especially dangerous, as it puts extra tensile load on cracks at the inner surface. The residual stress distribution in the pipe wall can be described approximately by a linear curve, but it is apparent from experimental results in available literature that the correct shape is rather similar to an exponential or quadratic curve $[8,9]$.

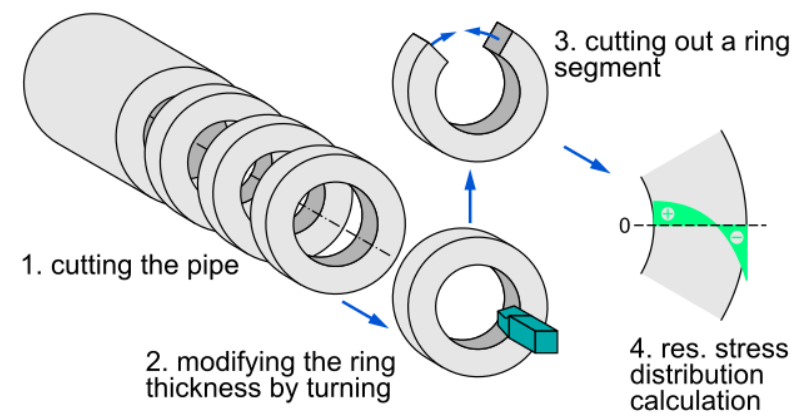

a)

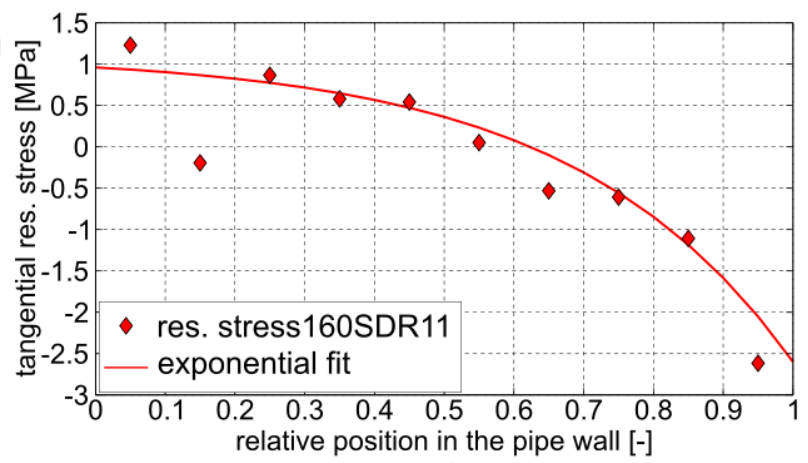

b)

Fig. 1: Scheme of the experiment (a) and the results for the PE pipe 160 SDR11 (b)

An investigation of the residual stress state in a PE pipe 160 SDR11 (outer diameter 160 $\mathrm{mm}$, wall thickness $14.6 \mathrm{~mm}$ ) was carried out. The results have already been published in [10]. The residual stress was determined by measuring deformation of slit rings - pipe was cut into several rings. The wall thickness of the rings was then modified on a lathe. Then, the 
rings were slit in the axial direction and a $120^{\circ}$ segment was cut out of each ring. This allowed the rings to deform as the tangential residual stress was relieved. The deflection of rings was measured. The residual stress distribution was calculated from the measured deflection using evaluation method based on the theory of a curved beam bending (the whole procedure is described in detail in [11]). Scheme of the experiment and the results for the pipe 160 SDR11 are in Fig. 1. The plotted distribution was later used as one of the loads in the model of the pipe.

\section{Soil loads}

When buried, pipes are subjected to external pressure caused by the surrounding soil. The highest load is acting in the vertical direction, because it is the result of the soil weight and additional loads caused by traffic, if the pipe is laid under a road. As plastic pipes are not as stiff as concrete or steel pipes, they always deform in the vertical direction, which then causes reaction of the soil in the horizontal direction. The calculations were made for radial loads only, the soil loads acting on the length of the pipe and causing the pipe bending in longitudinal direction (in the sense of beams lying on elastic foundation, like in [12]) were not considered in this case

It is quite difficult to calculate the actual pressure acting on a pipe in the ground. There is a lot of possible combinations of types of embedding, parameters of the soil and additional loads. To calculate loads acting on the pipe 160 SDR11 in this contribution, the Austrian standard ÖNORM B5012 [13] was used, similar to article [14]. A conservative case was considered - pipe buried $0.5 \mathrm{~m}$ under the surface with heavy traffic loads. If the pipe was buried deeper, the traffic loads would not have such a significant effect and the vertical loads caused just by the soil would by much smaller, which is why the shallow buried pipe is the more conservative case. The loads acting on the pipe are schematically pictured in Fig. 2 . The load case consists of vertical pressure $q_{v}$, horizontal pressure $q_{h}$ and the vertical rection of the soil $q_{v r}$. The horizontal reaction of the soil $q_{h} *$ is also present to account for the fact that the deflection of the pipe causes additional reaction of the soil.

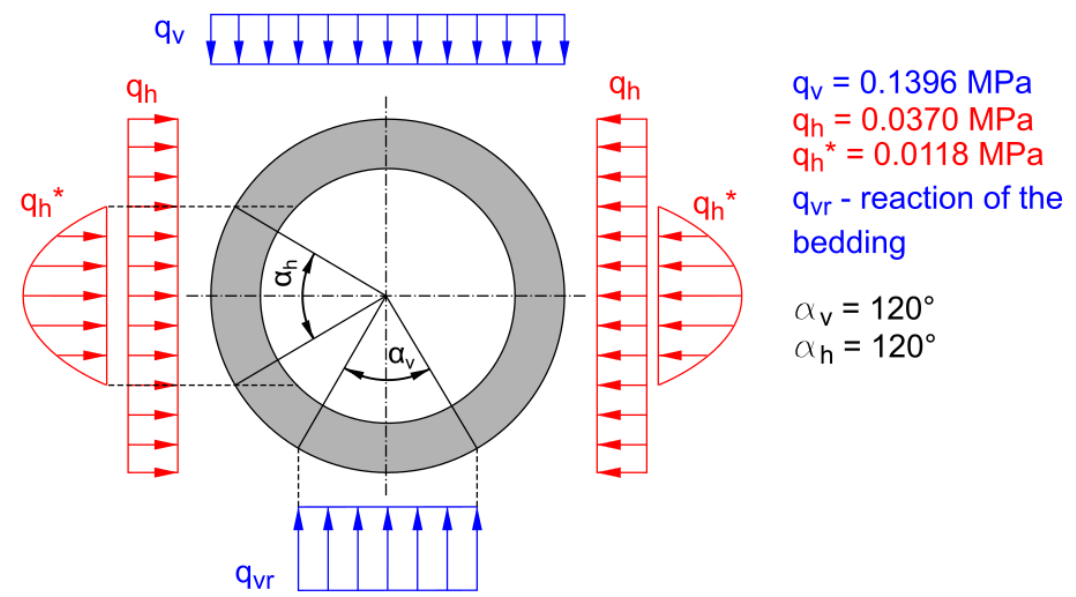

Fig. 2: Soil loads acting on a pipe 160 SDR11, calculated according to ÖNORM B5012

\section{Simulation of crack growth in the pipe 160 SDR11 and lifetime calculation}

A finite element model of the PE pipe 160 SDR11 with a semi-elliptical crack was set up. The crack was placed at the bottom of the pipe, as that is the place with largest tangential stress when internal pressure, residual stress and soil pressure are acting on the pipe at once (that was found out by FEM stress calculation of the pipe that did not contain any crack). Linear elastic material model was used, Young' modulus $E=1030 \mathrm{MPa}$, Poisson's ratio $\mu=$ 
0.33. The viscoelastic character of the real material was neglected in modelling. The linear elastic model was chosen because the following crack analysis is based on linear elastic fracture mechanics that also assumes linear elastic material. See the mesh of the model with boundary conditions in Fig. 3a. Note that the symmetrical boundary conditions were used instead of creating a full model of the pipe in order to save calculation time. However, the symmetrical boundary conditions do not fix the pipe in the vertical direction. Coupling of nodes was used for that because it fixes the model in place, but it preserves the ability of the model to deform. The model was loaded by internal pressure in the range of $0,5-1 \mathrm{MPa}$ (which is a slightly higher than the commonly allowed pressure in the water distribution systems) on the inside, external pressure on the outside and residual stress was included in the wall using definition of the initial state of the finite elements.

The elliptical crack was propagated through the model of the pipe in several iterations the crack length $a$ was changed in every iteration. Stress intensity factor was calculated for every crack length to obtain the dependency of the stress intensity factor on the crack length. This dependency was calculated for three loading cases - pipe loaded by internal pressure (1 $\mathrm{MPa}$ ) only, pipe loaded by internal pressure and residual stress (according to Fig. 1b) and pipe loaded by internal pressure, residual stress and soil pressure (according to Fig. 2). The results are plotted in Fig. 3b. The functions of stress intensity factors were obtained by fitting the results with polynomial functions. Then, these functions were used to calculate lifetime estimations of the pipe 160 SDR11.



a)

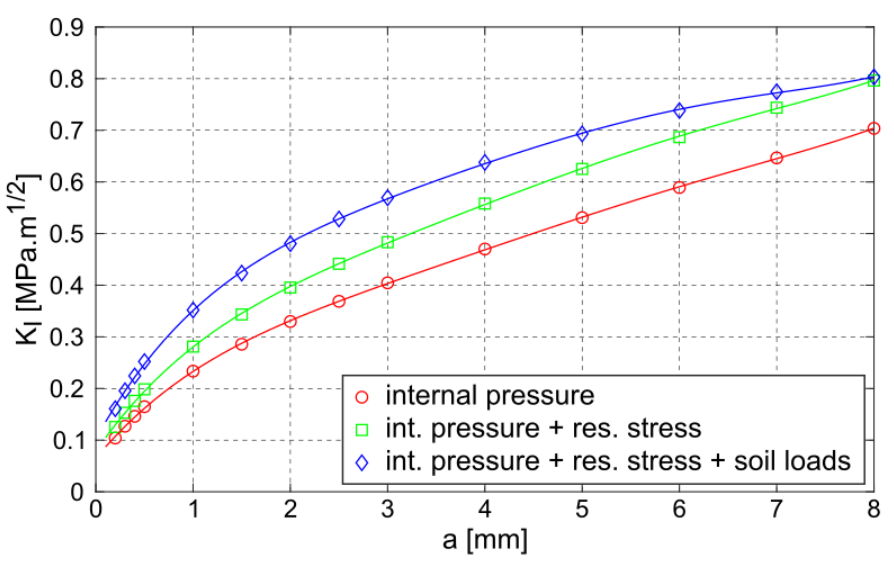

b)

Fig. 3: FEM model of the pipe with a crack (a) and the calculated stress intensity factors as functions of crack length $a(b)$

To successfully carry out the lifetime calculation, material parameters characterizing the crack kinetics in PE were needed. These parameters were determined by CRB (cracked round bar) tests $-A=7.578 \times 10^{-7}, m=6.728$ [15]. Initial defect size was set to $0.4 \mathrm{~mm}$, final crack size $7.3 \mathrm{~mm}$ (half of the pipe wall). The estimation of time to failure by SCG $t_{\mathrm{SCG}}$ was calculated by integration of the power law (1)

$$
t_{S C G}=\int_{a_{\text {ini }}}^{a_{f}} \frac{d a}{A\left(K_{I}(a)\right)^{m}}
$$

The $a_{i n i}$ and $a_{f}$ stand for the initial and final crack length. The $t_{S C G}$ is the estimation of the lifetime. It covers only the time of the actual crack propagation by SCG; the time spent by the crack initiation is not included. This means that the results are still very conservative, as the crack initiation can easily take up to $50 \%$ of the total lifetime. The results are in Table 1; 
there is a graphic representation of the results in Fig. 4. The values of lifetime are plotted versus the values of hoop stress $\sigma_{t}$. This is a theoretical value of hoop stress caused by the internal pressure only; the plot then resembles the results of hydrostatic pressure tests.

Table 1: Calculated lifetime estimations for the pipe 160 SDR11 in different load cases

\begin{tabular}{ll} 
Case & Estimated lifetime (years) \\
\hline Internal pressure & 3058 \\
\hline Int. pressure + res. stress & 876 \\
\hline Int. pressure + res. stress + soil loads & 182 \\
\hline
\end{tabular}

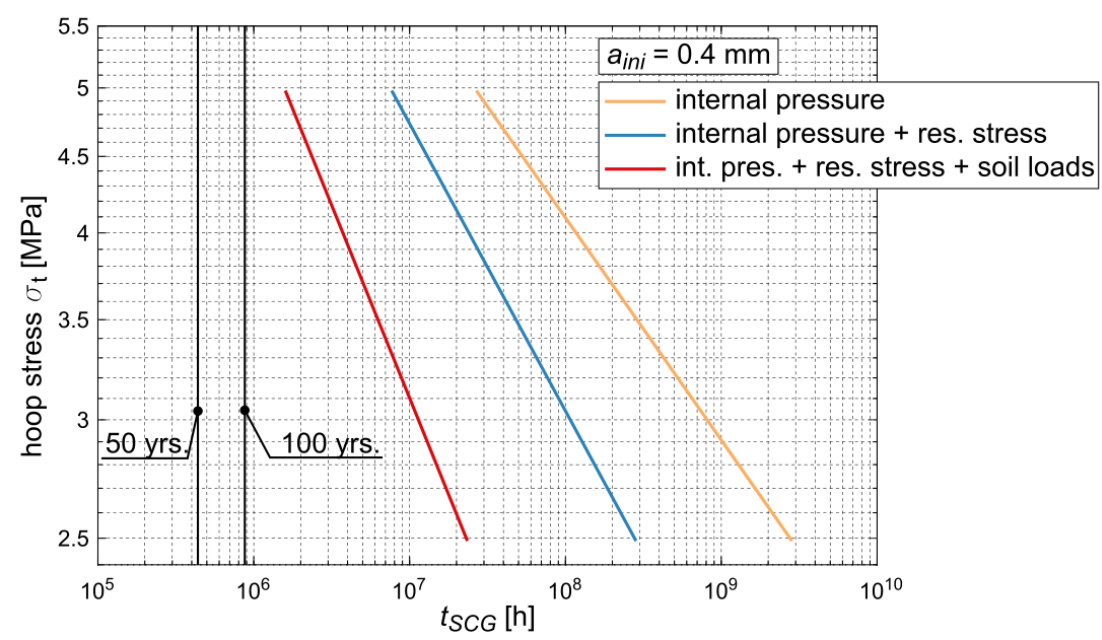

Fig. 4: Graphic representation of the lifetimes calculated for different cases of load combinations

\section{CONCLUSION}

This paper was focused on the lifetime calculation of the PE pipe 160 SDR 11. The linear elastic fracture mechanics approach was used to calculate the lifetime. The lifetimes were calculated for three different load cases - pipe loaded by internal pressure, pipe loaded by internal pressure and residual stress, and pipe loaded by internal pressure, residual stress and soil pressure. As the first step in the lifetime calculation, stress intensity factor functions had to be established using FEM model of the pipe with a propagating crack. The FEM model used linear elastic isotropic material model; the viscoelastic character of the material was neglected. These stress intensity factor functions were then used in the power law integration, that provided lifetime estimations.

The results show clearly that residual stress and soil loads affect the lifetime estimations quite significantly, as they bring the lifetime of the pipe to a fraction of the value for the pipe loaded only by internal pressure. Including these loads in the lifetime calculations also brings the results to more realistic values, as the estimated lifetimes for pipes loaded by internal pressures only are rather unrealistic. However, the calculated lifetimes are still well above the desired value of 50 years for PE pipes and they even exceed 100 years, even though conservative conditions were applied and the estimation does not include the crack initiation time, which could prolong the total lifetime by another $20-50 \%$. It means that the pipes in operation would not fail as a result of the SCG mechanism, but rather due to degradation of the mechanical properties of the material after a long time in operation.

\section{ACKNOWLEDGEMENTS}

Results were obtained using equipment from the Large Infrastructures for Research, Experimental Development and Innovation - project IPMinfra, LM2015069. The research was 
also funded from the COMET PCCL K1 - Center in Polymer Engineering and Science - a COMET-program of the Federal Ministry for Transport, Innovation, and Technology, and the Federal Ministry for Economy, Family, and Youth with contributions by the Department of Polymer Engineering and Science, University of Leoben (Austria). The PCCL is funded by the Austrian government and the state governments of Styria and Upper Austria.

\section{REFERENCES}

[1] Krishnaswamy, R. K. "Analysis of ductile and brittle failures from creep rupture testing of highdensity polyethylene (HDPE) pipes", Polymer 46 (25), pp. 11664 - 11672, 2005. DOI: https://doi.org/10.1016/j.polymer.2005.09.084

[2] Brömstrup, H. "PE 100 pipe systems", 3rd ed., Vulkan-Verlag, Essen, Germany, 2009. ISBN 978-3-8027-2759-7

[3] Pinter, G., Haager, M., Balika, W., Lang, R. W. "Fatigue crack growth in PE-HD pipe grades", Plastics, Rubber and Composites 34 (1), pp. 25 - 33, 2005. DOI: https://doi.org/ $10.1179 / 174328905 X 29758$

[4] Nezbedová, E., Hutař, P., Zouhar, M., Knésl, Z., Sadílek, J., Náhlík, L. "The applicability of the Pennsylvania Notch Test for a new generation of PE pipe grades", Polymer Testing 32 (1), pp. 106 - 114, 2013. DOI: https://doi.org/10.1016/j.polymertesting.2012.09.009

[5] Hutař, P., Ševčík, M., Náhlík, L., Pinter, G., Frank, A., Mitev, I. “A numerical methodology for lifetime estimation of HDPE pressure pipes", Engineering Fracture Mechanics 78 (17), pp. 3049 - 3058, 2011. DOI: https://doi.org/10.1016/j.engfracmech.2011.09.001

[6] Frank, A., Hutař, P., Pinter, G. "Numerical assessment of PE 80 and PE 100 pipe lifetime based on Paris-Erdogan equation" Macromolecular Symposia 311 (1), pp. 112 - 121. DOI: https://doi.org/10.1002/masy.201000096

[7] Janson, L-E. "Plastics pipes for water supply and sewage disposal", $3^{\text {rd }}$ ed. Borealis, Stockholm, Sweden, 1999.

[8] Williams, J. G., Hodgkinson, J. M., Gray, A. "The determination of residual stresses in plastic pipe and their role in fracture", Polymer Engineering \& Science 21 (13), pp. 822 - 828, 1981. DOI: https://doi.org/10.1002/pen.760211304

[9] Choi, S., Broutman, L. J. "Residual stresses in plastic pipes and fittings III. - Effect on stable crack growth behaviour". Polymer (Korea) 21, pp. 83 - 92, 1997.

[10] Poduška, J., Hutař, P., Kučera, J., Frank, A., Sadílek, J., Pinter, G., et al. "Residual stress in polyethylene pipes", Polymer Testing 54 (September 2016), pp. 288 - 295, 2016. DOI: https://doi.org/10.1016/j.polymertesting.2016.07.017

[11] Poduška, J., Kučera, J., Hutař, P., Ševčík, M., Křivánek, J., Sadílek, J., et al. "Residual stress distribution in extruded polypropylene pipes", Polymer Testing 40 (December 2014), pp. 88 98, 2014. DOI: https://doi.org/10.1016/j.polymertesting.2014.08.006

[12] Valkovič V, Jančo R, Frydrýšek K. "The effect of landslide on gas pipeline”, Strojnicky časopis - Journal of Mechanical Engineering 66 (2), pp. 95 - 100, 2016. DOI: https://doi.org/10.1515/scjme-2016-0023

[13] ÖNORM B 5012: Statische Berechnung erdverlegter Rohrleitungen für die Wasserversorgung und die Abwasser-Entsorgung 2008.

[14] Ševčík, M., Arbeiter, F., Hutař, P., Pinter, G., Náhlík, L. "The Effect of Soil Load on Fracture Behaviour of Three-Layer Polymer Pipe for Non-Pressurised Applications", Key Engineering Materials 627, pp. 197 - 200, 2015. DOI: https://doi.org/10.4028/www.scientific.net/ KEM.627.197

[15] Frank, A., Arbeiter, F., Berger, I., Hutař, P., Náhlík, L., Pinter, G. "Fracture Mechanics Lifetime Prediction of Polyethylene Pipes", Journal of Pipeline Systems Engineering and Practice 10 (1), pp. 1 - 14, 2019. DOI: https://doi.org/10.1061/(ASCE)PS.1949-1204.0000356 